\title{
Distanásia e ortotanásia: práticas médicas sob a visão de um hospital particular
}

\author{
José Antônio Cordero da Silva ${ }^{1}$, Luis Eduardo Almeida de Souza ${ }^{2}$, Luísa Carvalho Silva ${ }^{3}$, Renan Kleber Costa Teixeira ${ }^{4}$
}

\section{Resumo}

Dentre os conceitos relacionados à terminalidade da vida, encontram-se a distanásia e a ortotanásia. Distanásia significa a obstinação terapêutica para adiar a morte iminente. Ortotanásia significa morte em seu processo natural, não prolongando o tratamento. Este estudo objetivou analisar a percepção de familiares de pacientes internados acerca da ortotanásia e distanásia, avaliando a alternativa mais aceita. Trata-se de estudo transversal e observacional, no qual foram entrevistados 190 familiares por meio de questionário padronizado contendo perguntas sobre aspectos sociais e conhecimento da temática. A maioria (64,2\%) manifestou preferência pela distanásia como conduta para seu familiar. Entre 122 participantes que desconheciam o significado de "estado terminal", 85,2\% optariam pela distanásia. Porém, entre os que conheciam o significado, 70,9\% optariam pela ortotanásia. O estudo indica a necessidade de trazer o tema para discussão da sociedade, sensibilizando-a a entender implicações individuais e coletivas do prolongamento da vida em situação de sofrimento.

Palavras-chave: Estado terminal. Percepção social. População. Futilidade médica. Bioética.

\section{Resumen}

\section{Distanasia y ortotanasia: prácticas médicas bajo la visión de un hospital privado}

Entre los conceptos relacionados con el fin de la vida, están la distanasia y la ortotanasia. Distanasia significa la obtinación terapéutica para postergar la muerte inminente. Ortotanasia significa muerte en su proceso natural, sin prolongar el tratamiento. El objetivo de este estudio fue analizar la percepción de los familiares de pacientes hospitalizados sobre la ortotanasia y la distanasia, evaluando la alternativa más aceptada. En este estudio observacional y transversal 190 familiares fueron entrevistados mediante un cuestionario estandarizado que contenía preguntas sobre los aspectos sociales y de conocimientos sobre el tema. La mayoría (64,2\%) manifestó su preferencia por la distanasia como conducta para su familiar. De los 122 participantes que no conocían el significado de "estado terminal", el 85,2\% optaría por la distanasia. No obstante, entre los que conocían el significado, el 70,9\% optarían por la ortotanasia. El estudio indica la necesidad de plantear el tema para discusión de la sociedad, sensibilizándola a entender implicaciones individuales y colectivas de la prolongación de la vida en situación de sufrimiento.

Palabras-clave: Enfermedad crítica. Percepción social. Población. Inutilidad médica. Bioética.

\section{Abstract \\ Futility and orthotanasia: medical practices from the perspective of a private hospital}

Futility and orthotanasia are among the concepts related to the terminality life. Futility means therapeutic obstinacy to delay imminent death. Orthothanasia means death in its natural process, not prolonging treatment. The aim of this study was to analyze the perception of patients 'family members in private general hospital on orthotanasia and futility, assessing which the most widely accepted alternative is. This was a cross-sectional, observational study, in which 190 families were interviewed using a standardized questionnaire containing questions about social aspects and knowledge on the subject. Most respondents (64.2\%) opted for the realization of futility as a conduct for their relative. Of the 122 participants who did not know the meaning of "terminal condition", 85.9\% would choose futility. However, among those who knew what they meant, $70,9 \%$ would choose orthotanasia. The study indicates that this topic needs to be discussed by society, encouraging them to understand the individual and collective implications of life prolongations when suffering. Key words: Critical illness. Social perception. Population. Medical futility. Bioethics.

\section{Aprovação CEP Uepa (Plataforma Brasil): 263.968} 1. Doutor corderobel4@gmail.com 2. Graduando luisd_souza@hotmail.com 3. Graduando luisacs.Ics@gmail.com 4. Graduando
renankleberc@hotmail.com - Universidade do Estado do Pará (Uepa), Belém/PA, Brasil.

\section{Correspondência}

José Antônio Cordero da Silva - Av. Governador José Malcher, 1.343 Apt ${ }^{\circ} 1.300$ CEP 66060-230. Belém/PA, Brasil.

Declaram não haver conflito de interesse. 
Embora a maioria dos óbitos no século XXI ocorra nos hospitais, os médicos são pouco treinados para cuidar do paciente vítima de doença terminal. Da dificuldade em aceitar a morte surge a discussão sobre o impasse entre os métodos artificiais para prolongar a vida e a escolha voltada a deixar a doença seguir sua história natural ${ }^{1}$. Estudo realizado por Moritz ${ }^{2}$ acerca do comportamento dos profissionais de saúde ante a morte verificou a necessidade de aprofundar o debate sobre os temas morte e terminalidade da vida. A autora observa que a presente cultura ocidental torna a morte assunto socialmente evitado e politicamente incorreto. A palavra morte frequentemente associa-se ao sentimento de dor.

No tocante aos médicos, formados para salvar e curar, a morte associa-se à sensação de fracasso ou erro. Diversos estudos mostram que o médico deve reconhecer a terminalidade e modificar sua conduta, passando da luta pela vida para a provisão do conforto ${ }^{2}$. Para que isso ocorra, faz-se essencial que seja ministrado o ensino sobre a morte e o morrer na formação acadêmica e o debate constante do tema durante a atuação profissional.

O aumento da prevalência de doenças terminais é fato atual a ser enfrentado por médicos, serviços de saúde e sociedade. Paradoxalmente, há carência de cuidados paliativos adequados, fazendo com que a maioria da população não esteja provida desta atenção. Além disso, há barreiras culturais, éticas, sociais e estruturais que impedem o oferecimento de cuidados apropriados a pacientes em fase final da vida. Ocorrem falhas e lacunas na formação de profissionais de saúde, bem como daqueles egressos de outras áreas do conhecimento, às quais somam-se enormes deficiências nos sistemas de saúde e, ainda, desconhecimento acerca da reflexão proposta pela bioética e pelo biodireito ${ }^{3}$.

Com relação a essa questão, muito se discute quando é necessária a tomada de decisões no processo saúde/doença, considerando-se dois conceitos de grande relevância: distanásia e ortotanásia. A distanásia é a obstinação terapêutica com a finalidade de retardar a morte inevitável ${ }^{4}$; a ortotanásia é a morte em seu processo natural, no qual o paciente recebe apenas tratamento para eliminar ou diminuir suas dores e sofrimento ${ }^{5}$. Para auxiliar essa tomada de decisão por parte dos indivíduos com familiar terminal é fundamental uma formação humanística, ética e acadêmica da equipe de saúde em busca da relação médico-paciente solidária e humanizada, estabelecendo um vínculo de afeto e respeito entre pacientes e profissionais.
Na maioria dos países ocorrem muitas discussões sobre as decisões éticas do final da vida ${ }^{6}$. No mundo, a ortotanásia é praticada legalmente na Suécia, Inglaterra, Canadá, Japão e Brasil ${ }^{7}$. Contudo, segundo Hill ${ }^{8}$, apenas $4 \%$ das faculdades de medicina dos Estados Unidos se preocupam em transmitir ensinamentos sobre o processo de morte. Na América Latina é considerável a quantidade de pesquisas direcionadas a pacientes terminais e ao tema terminalidade da vida ${ }^{9}$, embora haja escassez de publicações sobre práticas e processos de tomadas de decisões, envolvimento de membros da família e pacientes, ou mudanças em tratamentos baseados na consciência e na responsabilidade requeridas pela reflexão bioética ${ }^{10}$.

De maneira geral, o evento morte é complexo e foco de dilemas éticos, bioéticos e profissionais, no qual emoções precisam ser trabalhadas e discutidas a partir de princípios bioéticos que podem ser resumidos por pequena palavra, que importa muito ao paciente terminal: dignidade. Assim, o objetivo desta pesquisa foi analisar a percepção de familiares de pacientes internados em hospital geral privado sobre a ortotanásia e a distanásia, avaliando qual das duas é a alternativa mais aceita.

Terminalidade da vida e a prática da distanásia e ortotanásia

O desenvolvimento de novas tecnologias, medicamentos e técnicas cirúrgicas fizeram com que houvesse surpreendente melhora no aumento da expectativa de vida na população. Atualmente, diversas doenças intratáveis apresentam tratamentos com boa evolução e bons prognósticos. Essas mudanças foram determinantes para criar o dogma de que sempre deve ser alcançada a cura do paciente ou o prolongamento máximo da vida do indivíduo ${ }^{11,12}$.

A história mostra essa mudança. Inicialmente, Hipócrates formulou como objetivos da medicina: aliviar o sofrimento dos enfermos, minimizar a agressividade da doença e recusar fazer tratamentos quando a medicina reconhece que não pode mais contribuir ${ }^{13}$. Essas prerrogativas foram mantidas até o início do século XVI, quando Francis Bacon considerou três finalidades para a medicina: preservação da saúde, a cura das doenças e o prolongamento da vida ${ }^{14}$.

A busca pelo prolongamento da vida, em pacientes que não apresentam condições de cura, sem a preocupação com a qualidade de vida e opinião do paciente, constitui uma futilidade ${ }^{14}$. Além de trazer maior sofrimento para o paciente e familiares, essa 
prática acaba por alocar recursos para tratamentos desnecessários, que poderiam ser utilizados por pacientes com patologias potencialmente curáveis ${ }^{15}$. Este prolongamento exagerado e desproporcional é denominado como distanásia, sendo sua prática proibida pelo Código de Ética Médica (CEM) ${ }^{10}$.

Contrapondo-se a este conceito, a ortotanásia é definida como a morte no tempo certo, sem abreviação nem prolongamentos desproporcionados do processo de morrer ${ }^{3,12}$, devendo este conceito ser diferenciado de eutanásia. Na eutanásia a morte ocorrerá devido à ação/omissão de terceiro. Contudo, a ortotanásia será decorrente da própria doença ${ }^{11,12}$. No Brasil, a prática da ortotanásia é autorizada pelo CEM ${ }^{10}$, mas até o momento não há leis federais nacionais para regulamentá-la ${ }^{12}$.

\section{Método}

A presente pesquisa caracteriza-se como transversal, descritiva, observacional e de análise quantitativa. Aprovada no Comitê de Ética em Pesquisa da Universidade do Estado do Pará, foi realizada entre os meses de junho e julho de 2013. Foram entrevistados 190 acompanhantes dos pacientes internados no Hospital Porto Dias, um hospital privado na cidade de Belém (Pará). Fundado em 1995, é referência em atendimento geral de alta complexidade, com enfoque em traumatologia, neurocirurgia, urgência e emergências clínicas e cirúrgicas. Possui 270 leitos, divididos em apartamentos (135), enfermarias (45), leitos de UTI (52) e pronto-atendimento (38).

A pesquisa incluiu os familiares de pacientes curáveis e em estado terminal internados, sendo permitido mais de um acompanhante por paciente. Os critérios de exclusão foram: acompanhantes menores de 18 anos; os que se recusaram a participar da entrevista ou assinar o termo de consentimento livre e esclarecido - que informava detalhadamente os objetivos do estudo.

Foi realizada entrevista - baseada em questionário (Anexo 1) - com o acompanhante do paciente, em local reservado e longe do enfermo. $O$ questionário continha perguntas relacionadas às condições sociais (sexo, estado civil, idade, grau de escolaridade, raça/cor) e ao conhecimento geral (conceitos sobre ortotanásia e distanásia, qual atitude tomaria com familiar em estado terminal) acerca das práticas da distanásia e ortotanásia. Os participantes foram questionados acerca do conhecimento sobre "doença terminal" e os que afirmaram desconhecer o significado da expressão receberam padronizada explicação dos pesquisadores, bem como os que referiam não conhecer os conceitos de distanásia e ortotanásia - buscando, contudo, não influenciar a escolha de qual método optar. Dessa forma, puderam prosseguir no questionário e responder se possuíam ou não um familiar em estado terminal.

Foi utilizado o software BioEstat ${ }^{\circledR} 5.3$ para realizar a análise estatística, o teste Contingência em C e o teste Exato de Fisher para comparar as variáveis analisadas com a preferência pela distanásia ou ortotanásia. Para rejeitar a hipótese de nulidade foi adotado um $p$ menor que $5 \%$.

\section{Resultados}

Foram entrevistados 190 acompanhantes de pacientes em todos os setores do hospital durante o período estudado. Do total, $106(55,7 \%)$ eram muIheres e $84(44,3 \%)$ homens, a idade variou de 18 a 78 anos, sendo a média de $41,71 \pm 14,90$ anos. Quanto ao estado civil, 86 eram casados (45,3\%); 86 $(45,3 \%)$, solteiros; $11(5,7 \%)$, viúvos e sete $(3,7 \%)$, divorciados. Em relação à religião constatou-se que $111(58,4 \%)$ dos entrevistados eram católicos; 51 $(26,8 \%)$, protestantes; dois (1\%), espíritas e os demais $(26-13,8 \%)$ declararam não seguir nenhuma religião.

Em relação à escolaridade, dois (1\%) participantes eram analfabetos, nove $(4,7 \%)$ cursaram o fundamental incompleto; 18 (9,5\%), o fundamental completo; 14 ( $7,4 \%)$, o ensino médio incompleto; 65 (34,2\%), o ensino médio completo; $22(11,6 \%)$, o ensino superior incompleto; 38 (20\%), o ensino superior completo; três $(1,6 \%)$ possuíam mestrado e $19(10 \%)$ não responderam.

Quando questionados, 36 (19\%) apresentavam conhecimento sobre o significado de distanásia e ortotanásia. Desse total, $21(58,3 \%)$ preferiam a realização da distanásia; 14 (38,9\%), a ortotanásia; e um não apresentava opinião sobre o tema $(2,8 \%)$. A Tabela 1 mostra a escolha dos participantes em relação à distanásia ou ortotanásia, após a explicação do conceito. As variáveis sexo $(p=0,5309)$, idade $(p=0,7447)$, escolaridade $(p=0,0991)$, estado civil $(p=0,1797)$ e religião $(p=0,8553)$ não influenciaram a opinião do paciente na escolha entre distanásia ou ortotanásia. 
Tabela 1. Opção por distanásia ou ortotanásia como conduta ao seu familiar

\begin{tabular}{|c|c|c|}
\hline Opção & Quantidade & $\%$ \\
\hline Distanásia & 122 & 64,2 \\
\hline Ortotanásia & 62 & 32,6 \\
\hline Nenhuma & 6 & 3,2 \\
Total & 190 & 100 \\
\hline
\end{tabular}

Fonte: questionário de pesquisa.

O conhecimento sobre o significado de estado terminal influenciou na escolha dos participantes $(p=0,0298)$. Dentre os que o conheciam, $44(70,9 \%)$ optariam pela ortotanásia e $18(29,1 \%)$ pela distanásia. Entre os que o desconheciam, $104(85,2 \%)$ escolheriam a distanásia e apenas $18(14,8 \%)$ a ortotanásia. Tal fato pode ser evidenciado na Tabela 2, na qual a maioria dos que não possuíam conhecimento sobre doença terminal optaram pela distanásia e, daqueles que tinham, pela ortotanásia. Após breve explicação acerca do termo "doença terminal", observou-se que do total de entrevistados 71 (37,3\%) diziam ser acompanhantes de pacientes terminais fato que não influenciou na escolha entre distanásia ou ortotanásia $(p=0,33)$.

Tabela 2. Associação entre conhecimento de estado terminal e opção pela distanásia e ortotanásia

\begin{tabular}{|c|c|c|c|}
\hline $\begin{array}{c}\text { Conhecimento } \\
\text { sobre doença } \\
\text { terminal }\end{array}$ & $\begin{array}{c}\text { Opção pela } \\
\text { ortotanásia }\end{array}$ & $\begin{array}{c}\text { Opção pela } \\
\text { distanásia }\end{array}$ & Total \\
\hline Sim & 44 & 18 & 62 \\
Não & 18 & 104 & 122 \\
Não optaram & - & - & 6 \\
\hline Total & $\mathbf{6 2}$ & $\mathbf{1 2 2}$ & $\mathbf{1 9 0}$ \\
\hline
\end{tabular}

Fonte: questionário de pesquisa. $p=0,0298$ (Exato de Fischer).

O estudo mostrou que $47(24,7 \%)$ pacientes haviam conversado com seus acompanhantes sobre terminalidade; que $83(43,7 \%)$ pacientes não haviam conversado e que $60(31,6 \%)$ entrevistados não sabiam se o paciente havia conversado com algum outro acompanhante, e considerou que este fato não influenciou na escolha entre distanásia ou ortotanásia $(p=0,45)$. Contudo, quando questionados se o familiar internado havia conversado com a equipe de saúde sobre a realização de tratamentos intensivos (Tabela 3), 55 (28,9\%) afirmaram ter conversado; 69 (36,3\%) que este não conversou e 60 $(31,6 \%)$ não sabiam se o paciente havia conversado.
Ressalte-se que quando os profissionais de saúde haviam conversado sobre a realização de tratamentos intensivos com o paciente, os acompanhantes optaram pela escolha da distanásia $(p=0,0098)$.

Tabela 3. Associação entre a opção do entrevistado e se o familiar internado havia conversado com a equipe médica sobre tratamentos intensivos

\begin{tabular}{|c|c|c|c|}
\hline $\begin{array}{c}\text { Familiar internado } \\
\text { conversou com a } \\
\text { equipe }\end{array}$ & $\begin{array}{c}\text { Opção pela } \\
\text { ortotanásia }\end{array}$ & $\begin{array}{c}\text { Opção pela } \\
\text { distanásia }\end{array}$ & Total \\
$\begin{array}{c}\text { Familiar internado } \\
\text { não conversou } \\
\text { com a equipe } \\
\begin{array}{c}\text { Desconheciam se } \\
\text { o familiar havia } \\
\text { conversado com a } \\
\text { equipe }\end{array}\end{array}$ & 34 & 35 & 65 \\
$\begin{array}{c}\text { Não optaram } \\
\text { por nenhum } \\
\text { procedimento }\end{array}$ & - & - & 60 \\
\hline Total & 48 & 76 & 190 \\
\hline
\end{tabular}

Fonte: questionário de pesquisa. $\mathrm{p}=0,0098$ (Exato de Fischer).

\section{Discussão}

A escolha da atitude a tomar diante da morte iminente de um ente querido é uma das mais difíceis que pode ocorrer na vida de um indivíduo ${ }^{10}$. 0 período próximo à morte de um familiar ou pessoa querida é um momento de reflexões e mudanças na estrutura psicológica, afetiva, social e física de uma família ou de um grupo social. Desse modo, torna-se nítida a necessidade de produzir análises profundas sobre medos, receios e dúvidas das pessoas que possuíram ou possuem familiares e amigos com algum agravo à saúde ${ }^{16}$. Essas reflexões são o foco do presente estudo.

Diversos aspectos - questões culturais, sociais e até demográficas - podem interferir na decisão de que atitude tomar ante a morte iminente de um familiar ${ }^{17}$. Nota-se, no estudo, grande tendência à escolha do método da distanásia, o que pode ter ocorrido pela condição econômica elevada dos entrevistados. Observa-se que estes desejam prolongar ao máximo a vida do ente querido, considerando-se a disponibilidade de tratamentos qualificados e sofisticados à pessoa internada. 
Tornou-se evidente a preferência pela distanásia entre os entrevistados que não tinham conhecimento sobre doença terminal (Tabela 2). A população não conseguiu compreender que o paciente em estado terminal invariavelmente falecerá e que, para ele, a realização da distanásia apenas será um desconforto, um sofrimento a mais, além do fato de que será exposto e ficará afastado do convívio de seus familiares, de seu habitat e da rotina pessoal ${ }^{18}$. Além disso, complementa-se o fato de os próprios entrevistados terem relatado não conhecer o significado dos termos estudados.

Fatores como sexo, idade, estado civil e escolaridade não influenciaram na decisão do entrevistado acerca de que atitude tomar diante da fase terminal da vida. Assim, acredita-se que fatores pessoais e individuais não sejam de relevância ou importância e haja um senso crítico comum numa determinada população que serve de base para a escolha. Outro ponto de grande relevância é o afeto consolidado em toda a convivência com o familiar que, aliado ao dogma de que a função do médico é sempre salvar vidas ${ }^{19}$, faz com que seja difícil para os familiares desistirem de lutar pela vida do ente, buscando sempre alternativas com o objetivo de maximizar sua sobrevida.

Contudo, o fato do estado civil não interferir em tal escolha é notável visto que essa correlação ficou explícita em diversos estudos ${ }^{20,21}$ realizados com pessoas que possuem vínculos matrimoniais com pacientes terminais. A condição de cônjuge modifica a escolha, sendo relacionada à tendência de optar pela ortotanásia, em decorrência do acompanhante colocar-se na posição do doente terminal, sua pessoa amada ${ }^{21}$. A grande quantidade de solteiros entrevistados na pesquisa pode ter alterado tal correlação, já que muitos não têm a experiência de um relacionamento duradouro, com convivência mais intensa e dependência mútua, o que implica que outros fatores afetem sua escolha.

Os aspectos religiosos são de suma importância para a melhora do bem-estar geral do paciente em estado terminal, proporcionando reflexões acerca de uma "vida pós-morte" e provendo um aumento da "paz" interior do doente ${ }^{22}$. Alguns estudos demonstram isto como fator preponderante para a escolha do tratamento do enfermo ${ }^{23}$. No presente estudo, não se observou interferência da religião na escolha da distanásia ou ortotanásia. Esse resultado é importante, pois diversas instituições religiosas em todo o mundo adotam posicionamentos a respeito da escolha frente à terminalidade da vida ${ }^{24,25}$.
A ausência de relação estatística em relação à variável religião pode ter ocorrido devido a maior parte dos participantes acreditar em uma religião, corroborando com os achados deste estudo no qual a população tem preferência pela distanásia por acreditar na cura.

Outro fator, que pode ter influenciado na escolha dos acompanhantes, foi o estudo ter sido realizado num hospital geral, no qual o prognóstico dos pacientes, na maioria dos casos, é bom. Assim, os familiares apresentam dificuldade em aceitar a morte iminente, apegando-se a esperança de que algo positivo ocorra e o doente consiga a cura ${ }^{16}$. Diferente é o que ocorre num hospital oncológico, onde os familiares já estão sofrendo há algum tempo e podem ter recebido um preparo maior em relação à morte do ente querido.

A pesquisa realizada mostra a interferência de dois fatores na escolha do tema: a compreensão do estado terminal e se o ente querido do familiar havia dialogado com a equipe de saúde sobre terminalidade da vida. Os entrevistados que referiram que seu familiar havia conversado com a equipe optaram pela distanásia (Tabela 3). Estudos evidenciaram que mais da metade dos médicos apresentam dificuldade para falar com os pacientes sobre o tema morte ${ }^{26,27}$. Consequentemente pode ocorrer possível interferência da própria equipe de saúde junto ao doente, incentivando-o a prosseguir no tratamento e exaltando as qualidades da ciência no prolongamento da vida ${ }^{23}$, haja vista a dificuldade de aceitar a morte e de associá-la ao fracasso ou erro.

Um mecanismo proposto para reduzir a distanásia é a manifestação da vontade antecipada ${ }^{26-29}$. Nesta, o paciente previamente informa se deseja ou não, quando não for possível a cura, que sejam empregados métodos de prolongamento artificial da vida. Este mecanismo ainda não apresenta uma legislação vigente no Brasil, mas uma pesquisa de Piccini ${ }^{29}$ evidenciou que significativa parcela dos médicos respeita a escolha do paciente, mesmo este mecanismo não apresentando valor legal, e outra pesquisa de Campos e colegas ${ }^{30}$ detectou que a quase totalidade dos pacientes e familiares quer ter suas vontades antecipadas respeitadas. Neste contexto, para suprir o vazio legal, o Conselho Federal de Medicina (CFM) emitiu a Resolução 1.995/12 ${ }^{31}$, que instituiu as diretivas antecipadas de vontade no âmbito da ética médica brasileira como um instrumento que pode contribuir para a inibição da distanásia.

O presente estudo evidenciou a necessidade de maior discussão sobre a terminalidade da vida, que grande parcela da população desconhece. Muito 
se divulga e discute sobre a "eutanásia", devido a sua presença marcante na mídia, porém os debates sobre os temas "distanásia e ortotanásia" são reduzidos, não tendo tanta importância quanto o primeiro ${ }^{23,32}$. Este fato pode estar ocorrendo pela ausência de leis federais nacionais para regulamentar a prática da ortotanásia ${ }^{27-31}$, havendo apenas um projeto de lei ${ }^{33} \mathrm{em}$ tramitação na Comissão de Constituição, Justiça e Cidadania do Senado Federal, embora esteja em vigor a regulamentação do CFM direcionada aos médicos por meio do Código de Ética Médica ${ }^{10}$, em seu artigo 41, e da Resolução CFM 1.805/06 ${ }^{34}$, que permite ao médico limitar ou suspender procedimentos e tratamentos que prolonguem a vida do doente em fase terminal.

\section{Considerações finais}

Observou-se que mesmo com a forte divulgação nas mídias a respeito do assunto terminalidade da vida, a maior parte dos indivíduos entrevistados desconhece seus conceitos e reflexões básicas, sendo óbvia a necessidade de abordagem mais ampla de toda a equipe de saúde, visando esclarecer as possíveis dúvidas acerca da situação do paciente.

A maioria dos entrevistados optou pela realização da distanásia frente à possível morte iminente do familiar. Constatou-se que essa escolha não sofreu intervenção dos fatores sexo, idade, estado civil, escolaridade e aspectos religiosos. Porém, o estudo evidenciou grande interferência em relação ao familiar possuir conhecimento acerca do significado de doença terminal, bem como da existência prévia de diálogo a respeito do fim da vida, entre o doente e sua família. Demais trabalhos deverão ser realizados para preencher as lacunas deixadas por esta pesquisa, analisando-se, por exemplo, outros ambientes como hospitais públicos, faixas etárias específicas etc.

Os dados encontrados nesta pesquisa podem contribuir para melhorar o atendimento, acompanhamento psicossocial e apoio, tanto aos pacientes internados quanto aos familiares envolvidos com pacientes em estado terminal. As informações levantadas podem contribuir para aperfeiçoar os serviços de saúde, orientando gestores e equipes acerca de como melhorar o atendimento dos seus pacientes.

O trabalho também permitiu constatar que há necessidade de preparar melhor as equipes de saúde para o acolhimento dos parentes e amigos de um paciente terminal. Essa constatação revela-se especialmente pertinente em relação aos médicos, cuja graduação ensina a combater a morte, inclusive por pressão ou temores jurídicos. Há, em certos casos, na graduação e em outros níveis como na residência médica, ausência de ensino sobre a forma de conduzir e reagir em casos de impossibilidade de tratamento e cura de pacientes terminais.

Por fim, há necessidade premente de trazer o tema para a discussão em sociedade, informando as pessoas sobre o que é distanásia e ortotanásia, e sensibilizando-as para entender que o prolongamento da vida em situação de sofrimento pode vir a se tornar um pesado fardo para o paciente e para a sociedade.

\section{Referências}

1. Junges JR, Cremonese C, Oliveira EA, Souza LL, Backes V. Reflexões legais e éticas sobre o final da vida: uma discussão sobre ortotanásia. Rev. bioét. (Impr.). 2010;18(2):275-88.

2. Moritz RD. Os profissionais de saúde diante da morte do morrer. Rev. bioét. (Impr.). 2005;13(2):5163.

3. Garcia JBS. Eutanásia, distanásia ou ortotanásia? Rev. Dor. 2011;12(1):3.

4. Morais IM. Autonomia pessoal e morte. Rev. bioét. (Impr.). 2010;18(2):289-309.

5. Martin LM. Eutanásia e distanásia. In: Costa SIF, Oselka G, Garrafa V, coordenadores. Iniciação à bioética. Brasília: Conselho Federal de Medicina; 1998. p. 171-92.

6. Batista KT, Seidl EMF. Estudo acerca de decisões éticas na terminalidade da vida em unidade de terapia intensiva. Com. Ciências Saúde. 2011;22(1):51-60.

7. Truog RD, Campbell ML, Curtis JR, Haas CE, Luce JM, Rubenfeld GD et al. Recommendations for endof-life care in the intensive care unit: a consensus statement by the American College [corrected] of critical care medicine. Crit Care Med. 2008;36(3):953-63.

8. Hill TP. Treating the dying patient: the challenge for medical education. Arch Intern Med. 1995;155(12):1.265-9.

9. Kipper DJ. Medicina e os cuidados de final de vida. Uma perspectiva brasileira e latino-americana. In: Pessini L, Garrafa V, organizadores. Bioética: poder e injustiça. São Paulo: Loyola; 2003. p. 409-14.

10. Conselho Federal de Medicina. Resolução CFM n 1.931, de 24 de setembro de 2009. Código de ética médica. Brasília: CFM; 2010. 
11. Marreiro CL. Responsabilidade civil do médico na prática da distanásia. Rev. bioét. (Impr.). 2013;21(2):308-17.

12. Cruz MLM, Oliveira RA. A licitude civil da prática da ortotanásia por médico em respeito à vontade livre do paciente. Rev. bioét. (Impr.). 2013;21(3):405-11.

13. Jecker NS, Schneiderman LJ. Medical futility: the duty not to treat. Camb Q Healthc Ethics. 1993;2(2):151-9.

14. Oliveira MZPB, Barbas S. Autonomia do idoso e distanásia. Rev. bioét. (Impr.). 2013;21(2):328-37.

15. Fortes PAC, Pereira PCA. Priorização de pacientes em emergências médicas: uma análise ética. Rev. Assoc. Med. Bras. 2012;58(3):335-40.

16. Santana JCB, Rigueira ACM, Dutra BS. Distanásia: reflexões sobre até quando prolongar a vida em uma unidade de terapia intensiva na percepção dos enfermeiros. Bioethikos. 2010;4(4): 402-11.

17. Marengo MO, Flávio DA, Silva RHA. Terminalidade de vida: bioética e humanização em saúde. Medicina. 2009;42(3):350-7.

18. Teixeira RKC, Gonçalves TB, Silva JAC. A intenção de doar órgãos é influenciada pelo conhecimento populacional sobre morte encefálica? Rev. Bras. Ter. Intensiva. 2012;24(3):258-62.

19. Kind L. Intervenções diante da morte e o direito de morrer. Sau e Transf. Soc. 2013;4(3):7-15.

20. Capello EMCS, Velosa MVM, Salotti SRA, Guimarães HCQCP. Enfrentamento do paciente oncológico e do familiar/cuidador frente à terminalidade de vida. J Health Sci Inst. 2012;30(3):235-40.

21. Saraiva AMP. Suspensão de tratamento em unidades de terapia intensiva e seus fundamentos éticos. Rev. bioét. (Impr.). 2012;20(1):150-63.

22. Batista $S$, Mendonça ARA. Espiritualidade e qualidade de vida nos pacientes oncológicos em tratamento quimioterápico. Rev. bioét. (Impr.). 2012;20(1):175-88.

23. Amorin MMS, Sousa AC, Melo BR, Alcantara G, Morelo J. Eutanásia, ortotanásia e suicídio assistido: aspectos jurídicos, religiosos e éticos. XVI Congresso de Ciências da Comunicação na Região Sudeste. São Paulo; 2011.

24. Conselho Federal de Medicina. Entrevista ao CFM: CNBB apóia ortotanásia. [Internet]. (acesso 8 out. 2013). Disponível: http://portal.cfm.org.br/index.php?option=com_content\&view=article\&i $\mathrm{d}=23257$ :entrevista-ao-cfm-cnbb-apoia-ortotanasia\&catid=3

25. Pessini L. Terminalidade e espiritualidade: uma reflexão a partir dos códigos de ética médica brasileiros e leitura comparada de alguns países. O Mundo da Saúde. 2009;33(1):35-42.

26. Sánchez AV, Villalba SF, Romero PMG, Barragán SG, Delgado RMT, García M. Documento de voluntades anticipadas: opinión de los profesionales sanitarios de atención primaria. Sermergen. 2009;35(3):111-4.

27. Stolz C, Gehlen G, Bonamigo EL, Bortoluzzi MC. Manifestação das vontades antecipadas do paciente como fator inibidor da distanásia. Rev. bioét. (Impr.). 2011;19(3):833-45.

28. Romano BW, Watanabe CE, Troppmair S. Distanásia: vale a pena? Rev. SBPH. 2006;9(2):67-82.

29. Piccini CF, Steffani JÁ, Bonamigo EL, Bortoluzzi MC, Schlemper Jr BR. Testamento vital na perspectiva de médicos, advogados e estudantes. Bioethikos. 2011;5(4):384-91.

30. Campos MO, Bonamigo EL, Steffani JA, Piccini CF, Caron R. Testamento vital: percepção de pacientes oncológicos e acompanhantes. Rev. Bioethikós. 2012;6(3)253-9.

31. Conselho Federal de Medicina. Resolução CFM n 1.995, de 31 de agosto de 2012. Dispõe sobre as diretivas antecipadas de vontade dos pacientes. Diário Oficial da União. 31 ago. 2012:seção I, p. 269-70.

32. Pessini L. Distánasia: até quando investir sem agredir? Bioética. 1996;4(1):31-43.

33. Brasil. Projeto de lei $n^{\circ} 524$, de 25 de novembro de 2009. Dispõe sobre os direitos da pessoa em fase terminal de doença. [Internet]. Disponível: http://www.senado.gov.br/atividade/materia/ getPDF.asp?t=70253\&tp=1

34. Conselho Federal de Medicina. Resolução CFM n 1.805, de 9 de novembro de 2006. Na fase terminal de enfermidades graves e incuráveis é permitido ao médico limitar ou suspender procedimentos e tratamentos que prolonguem a vida do doente, garantindo-lhe os cuidados necessários para aliviar os sintomas que levam ao sofrimento, na perspectiva de uma assistência integral, respeitada a vontade do paciente ou de seu representante legal. Diário Oficial da União. 28 nov. 2006:seção I, p. 169.

\section{Participação dos autores}

Todos os autores participaram da elaboração e revisão do artigo. Luis Eduardo Almeida de Souza e Luísa Carvalho Silva realizaram a coleta de dados e a confecção do manuscrito. Renan Kleber Costa Teixeira realizou a análise estatística e a confecção do manuscrito. José Antônio Cordero da Silva orientou a pesquisa e realizou sua revisão crítica.

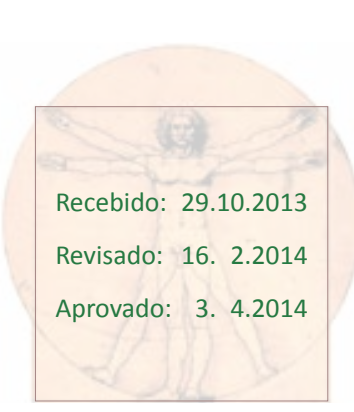


Anexo

\section{Questionário de pesquisa}

1- Idade:

2- Sexo:

( ) Masculino

( ) Feminino

3- Estado civil:

( ) Casado

( ) Solteiro

( ) Viúvo

( ) Divorciado

4- Grau de escolaridade:

( ) Analfabeto

( ) Fundamental incompleto

( ) Fundamental completo

( ) Ensino médio incompleto

( ) Ensino médio completo

( ) Ensino superior incompleto

( ) Ensino superior completo

( ) Mestrado ou doutorado

5- Raça/cor:

( ) Negra

( ) Parda

( ) Branca

( ) Indígena

6- Você tem conhecimento sobre distanásia e ortotanásia?

Sabe o que significa?

( ) Sim ( ) Não. O que é?

6.1 Se a resposta foi "Sim" para a pergunta 6, como você adquiriu conhecimento sobre esse tema?

7- Se fosse possível, qual das duas você optaria para ser tomada como conduta ao seu familiar? Por quê?
8- O(a) senhor(a) tem ideia do que é uma doença terminal? ( ) Sim ( ) Não

Em caso positivo, qual o significado

9- Você possui ou possuiu algum familiar em estado terminal? ( ) Sim ( ) Não

10- Qual é/era o diagnóstico do seu familiar?

11- Qual a sua orientação espiritual/religião?

( ) Católica Apostólica Romana

( ) Católica Ortodoxa

( ) Protestantismo

( ) Judaica

( ) Budista

( ) Islâmica

( ) Espiritismo

( ) Outra, qual?

12- Sua religião possui alguma orientação sobre a conduta a ser tomada no caso de pacientes terminais?

( ) $\operatorname{Sim}($ ) Não

12.1 Se sim, quais condutas seriam?

13- Você seguiria essa orientação?（） Sim（） Não

14- $O$ paciente que o(a) senhor(a) acompanha recebeu visita de algum membro da igreja/religião a que pertence? ( ) Sim ( ) Não

14.1 Se sim, como acha que o paciente reagiu à visita? Orientar a dar uma nota entre 0 a 10 , em que " 0 " seria Terrivelmente e " 10 " seria Perfeitamente. A nota " 5 " corresponde a Muito bem. Nota: 
Distanásia e ortotanásia: práticas médicas sob a visão de um hospital particular

15- O paciente já conversou com você sobre terminalidade da vida? ( ) Sim ( ) Não

16- O paciente já demonstrou/conversou com você sobre seus desejos de tratamento frente a situações agravantes - por exemplo, ressuscitação, tratamento intensivo, tratamento invasivo (cirurgia)?

( ) $\operatorname{Sim}($ ) Não
17- O paciente já demonstrou/conversou com o médico/ equipe médica sobre seus desejos de tratamento frente a situações agravantes - por exemplo, ressuscitação, tratamento intensivo, tratamento invasivo (cirurgia)? ( ) Sim ( ) Não( ) Não sabe 